\title{
Peertechz
}

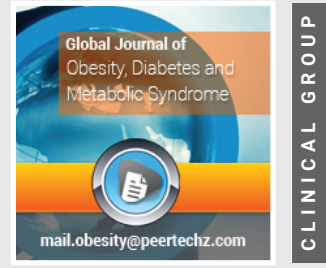

\section{Non adherence to physical activity recommendations and associated factors among Type 2 Diabetic patients in Illubabor zone, South West Ethiopia}

\author{
Rukiya Debalke ${ }^{1 *}$, Beakal Zinab² and Tefera Belachew ${ }^{2}$ \\ 'Department of Public Health, College of Health Science, Mettu University, Mettu, Ethiopia \\ ${ }^{2}$ Department of Nutrition and Dietetics, Faculty of Public Health, Jimma University, Jimma, Ethiopia
}

Received: 24 September, 2020

Accepted: 05 January, 2022

Published: 06 January, 2022

*Corresponding author: Rukiya Debalke, Department of Public Health, College of Health Science, Mettu University, Mettu, Ethiopia, Email: desti1984@gmail. com; rukdeb1983@gmail.com

ORCID: https://orcid.org/0000-0002-3827-0757

Keywords: Diabetes; Non-adherence; Physical activity recommendation

Copyright: (c) 2022 Debalke R, et al. This is an openaccess article distributed under the terms of the Creative Commons Attribution License, which permits unrestricted use, distribution, and reproduction in any medium, provided the original author and source are credited.

https://www.peertechzpublications.com

\section{Abstract}

Introduction: Diabetic patients' poor adherence to lifestyle recommendations leads to poor glycemic control and associated micro and macro-vascular complications; however most patients have difficulty in adhering to the lifestyle modifications including physical activity recommendations.

This study assessed the magnitude of non-adherence to physical activity recommendation and associated factors among type 2 diabetic patients attending follow up at government hospitals in llu Abba Bora Zone, southwestern Ethiopia.

Methods: Institution based cross-sectional study was conducted from March 19 to May 19, 2018, among 422 diabetic patients attending regular follow up at government hospitals in Illuababor Zone, Southwest Ethiopia, participants were selected using systematic sampling method. Physical activity adherence was assessed using Global Physical Activity Questionnaire [GPAQ]. Multivariable logistic regression was used to identify factors associated with diabetic patients' non-adherence to physical activity recommendations.

Results: The study found that $38 \%$ of diabetic patients were non-adherent to physical activity recommendations. The odds non-adherence to physical activity recommendations was independently associated with patients' sex (AOR=2 (95\%Cl:1.2, 3.4)), perceived severity of the illness (AOR=1.7 (95\%Cl:1.1, 2.8)) and self-efficacy $(\mathrm{AOR}=2.6(95 \% \mathrm{Cl}: 1 \cdot 6,4.4))$.

Conclusion and recommendations: High proportions of diabetic patients were non-adherent to physical activity recommendations. Evidence based and Patient centered management plan should be practiced. The results imply that integrating lifestyle modification education focussing on physical activity recommendations should be integrated into diabetic care.

\section{Introduction}

Diabetes is a group of metabolic diseases characterized by hyperglycemia resulting from defects in insulin secretion, insulin action, or both. Diabetes Mellitus is rapidly emerging as a major public health concern across the globe associated with increasing of aged populations, economic development, increasing urbanization, consumption of less healthy diets and reduced physical activity. According to International Diabetes Federation (IDF), about one out of every 11 adults worldwide has diabetes. In Africa 14.2 million adults have diabetes and by $2040,43.2$ million adults are expected to have diabetes. Ethiopia is also one of the countries affected by diabetes. According to the 2015 report of IDF, the number of adults aged 20-79 years, living with diabetes was 2.135 million (4.8\%), A study done in southwest Ethiopia found diabetes among $6 \%$ and $2.9 \%$ of populations in urban and rural areas, respectively [1].

Diabetes is associated with risk of both microvascular and macrovascular complications. Diabetic complications 
account for increased morbidity, disability, and mortality and exert stress in the economies of all countries, especially the developing ones [2-5].

Management of diabetes is challenging as it requires multiple therapeutic approaches including Self-Monitoring of Blood Glucose (SMBG), dietary and lifestyle modifications and administration of medications as per schedule. Regimen adherence problems are common in individuals with diabetes, thus making glycaemic control difficult to attain. The management plan should also be formulated as an individualized therapeutic alliance among the patient, family, physician and other members of the health care team [6]. Regular exercise has been shown to improve blood glucose control, reduce cardiovascular risk factors, contribute to weight loss, and improve well-being [7-9].

There is variation in the magnitude and determinants of non-adherence to physical activity recommendations across the globe. According to studies done in India, more than half of respondents were non-adherent to physical activity recommendations and physical activity adherence was significantly affected by family history of diabetes, respondents socioeconomic status, patients family size, busy schedule, education level, beliefs, health condition, poor memory, level of motivation, level of social and family support, frequent social gatherings, trust in health-care provider and marital status of participants [10-12]. Studies done in different parts of Ethiopia also reported varied magnitude adherence to physical activity ranging from $18.4-68.8 \%$ [13]. Wide-ranging factors associated with non-adherence to physical activity recommendation including level of education, monthly income, absence of clear instruction and busy schedule were identified [13,14].

Although various predictors of non-adherence to physical activity recommendations were identified, these factors are not typically even for all patients and vary across different populations. Thus, understanding the determinants of nonadherence to physical activity recommendations in local setting is crucial to implementing patient centered intervention approach. Therefore, this study aims to assess the magnitude of non-adherence to physical activity recommendations and its associated factors among type 2 diabetic patients in Illubabor zone.

\section{Method}

\section{Study setting and participants}

The study was conducted in Ilu Abba Bora Zone, Southwest Ethiopia, there are 2 public hospitals in the zone providing regular follow-up care for diabetic patients. These facilities provide service to all of the weekdays and patients collect their medication regularly on a monthly basis. Diabetic clinics provide services for an average of 20-22 patients per day. All adult type 2 diabetes patients who were on regular follow up at MKRH and Darimu Hospital NCD follow up clinic were the source populations while randomly selected adult type 2 diabetic patients who are on regular follow up at MKRH and Darimu Hospital NCD follow up units were study populations.
In the current study, patients who were unable to provide required information and newly diagnosed patients (who had less than at least three follow up visits) were excluded from the study.

Sample size was separately calculated for the outcome (physical activity non-adherence) and each explanatory variable using different parameters taken from previously published researches and finally the largest sample size was taken to ensure better representativeness. The final sample size was estimated with the following assumptions, expected proportion of for poor physical activity practice among diabetic patients to be $64 \%$ from a study done in Jimma University Specialized Hospital [15], with desired degree of precision 5\%, 95\% confidence level and 10\% non-response rate, then the final sample size become 389 . However, we were able to recruit more participants within the scheduled study period; as a result 422 participants were included for the current study. The final sample (422) was proportionally allocated to each hospital based on number of diabetic patients on regular follow up. Accordingly, 338 and 187 participants were included from Metu and Darimu Hospitals respectively. Finally, study participants were selected using systematic sampling technique.

\section{Data collection and measurement}

Interviewer administered semi-structured questionnaire was used to collect socio-demographic, patients health profiles including duration of disease, type of treatment, comorbidity and family history. Diabetic health belief was assessed using a total of 26 questions. Patients' perceived susceptibility to diabetes complications and perceived severity was assessed using five questions each, perceived benefit and barrier to physical activity regimen was assessed using four and eight questions, respectively. Likewise, self-efficacy towards following physical activity recommendations was assessed using four questions. The other section of the tool assessed emotional and active (instrumental support from family and non-family members) support which was modified from "The Diabetes Social Support Questionnaire-Family Version: developed in 2002" [16]. Physical activity adherence was assessed using Global Physical Activity Questionnaire (GPAQ), The Global Physical Activity Questionnaire was developed by WHO for physical activity surveillance in different countries [17]. Waist Circumference (WC) was measured midway between the inferior angle of the ribs at the midclavicular line and the suprailiac crest at the end of normal expiration to the nearest $1 \mathrm{~cm}$ using a non-stretchable rubber measuring tape. Participants were positioned in an upright, with arms relaxed at the side, feet evenly spread apart and body weight evenly distributed in accordance with the WHO recommendation [18]

\section{Data Processing and Analysis}

Data were coded and entered to Epi data version 3.1 and exported to SPSS windows version 20 for cleaning and analyses. Exploratory data analyses and descriptive statistics including proportion, percentage, ratios, frequency distribution, mean and standard deviation were used to describe the data. Wealth index was constructed using the Principal Component Analysis 
(PCA) from 27 items after checking all assumptions. Bivariate logistic regression analysis was done to see the association between individual explanatory and outcome variables, variables with $\mathrm{P}$-value $<0.25$ were a candidate for multivariable logistic regression analysis. Odds ratio with $95 \%$ C.I was used to measure the strength of association between dependent and independent variables. $P$ value $<0.05$ was used to declare level of statistical significance. The scores of each diabetic health belief were constructed by summing up the responses to generate a single score for each construct, Participants were labelled to have high or low level of each construct using mean value as a cut-off, patients social support status was also labelled based on mean value. The outcome variables were dichotomized based on amount of 600 METs per week as a cut-off.

\section{Operational and standard definitions}

Physical activity: refers to the bodily movement produced by the contraction of skeletal muscle that requires energy expenditure in excess of resting energy expenditure [19].

Adherence: The extent to which a person's behavior taking medication, following a diet and physical activity, and/or executing lifestyle changes corresponds with agreed recommendations from a health care provider [20].

Non Adherent to physical activity recommendation: are those who scored less than 600 METs per week based on the GPAQ incorporated scoring mechanism [21].

Adherent to physical activity recommendation: are those who scored greater than or equal to 600 METs per week based on the GPAQ incorporated scoring mechanism [21].

Abdominal obesity: Participants with waist circumference $>102 \mathrm{~cm}$ for men and $>88 \mathrm{~cm}$ for women [22]

\section{Ethical consideration}

Ethical approval was obtained from the Research and Ethical Committee of Jimma University, Permission letter was written for both Mettu Karl Referral and Darimu Hospital additionally informed consent was obtained from study participants after necessary explanation about the purpose of the study and the respondents' right to refuse or withdraw at any stage was fully realized. All the interviews with respondents were made under strict privacy.

\section{Results}

A total of 392 respondents participated in the study of which females account for $51.3 \%$. The mean age of respondents were $47(\mathrm{SD} \pm 13)$. Nearly two third $(63.8 \%)$ of respondents were married, $37.2 \%$ of them can't read and write while $43.1 \%$ of respondents were government employers. Similarly, more than half $(58.2 \%)$ of respondents were Oromo by ethnicity and one third of the participants were in the lowest wealth tertiles (Table 1).

\section{Clinical characteristics of study participants}

The mean duration of the illness since diagnosis was 6.9 $(\mathrm{SD} \pm 5.3)$ years, nearly half of $(46.4 \%)$ patients had family
Table 1: Socio-demographic Characteristics of diabetic patients attending regular follow-up at public health facilities in Illubabor zone, south west Ethiopia.

\begin{tabular}{|c|c|c|}
\hline Variables & Frequency ( $n=392)$ & Percentage \\
\hline $\begin{array}{c}\text { Sex } \\
\text { Male } \\
\text { Female }\end{array}$ & $\begin{array}{l}191 \\
201\end{array}$ & $\begin{array}{l}48.7 \\
51.3\end{array}$ \\
\hline $\begin{array}{l}\text { Marital status } \\
\text { Single } \\
\text { Married } \\
\text { Widowed } \\
\text { Separated }\end{array}$ & $\begin{array}{c}71 \\
250 \\
44 \\
27\end{array}$ & $\begin{array}{c}18.1 \\
63.8 \\
11.2 \\
6.9\end{array}$ \\
\hline $\begin{array}{c}\text { Educational level } \\
\text { Can't read and write } \\
\text { Primary } \\
\text { Secondary and vocational } \\
\text { College and above }\end{array}$ & $\begin{array}{c}146 \\
52 \\
120 \\
74\end{array}$ & $\begin{array}{l}37.2 \\
13.3 \\
30.6 \\
18.9\end{array}$ \\
\hline $\begin{array}{l}\text { Occupational status } \\
\text { Self employed }\end{array}$ & $\begin{array}{l}111 \\
112\end{array}$ & $\begin{array}{l}28.3 \\
28.6\end{array}$ \\
\hline $\begin{array}{l}\text { Gov't employed } \\
\text { unemployed }\end{array}$ & 169 & 43.1 \\
\hline $\begin{array}{c}\text { Ethnicity } \\
\text { Oromo } \\
\text { Amhara } \\
\text { Gurage } \\
\text { Tigre } \\
\text { Others(???) }\end{array}$ & $\begin{array}{c}228 \\
\\
82 \\
25 \\
48 \\
9\end{array}$ & $\begin{array}{c}58.2 \\
\\
\\
20.9 \\
6.4 \\
12.2 \\
2.3\end{array}$ \\
\hline $\begin{array}{c}\text { Household wealth } \\
\text { Low } \\
\text { Middle } \\
\text { High }\end{array}$ & $\begin{array}{l}130 \\
134 \\
128\end{array}$ & $\begin{array}{l}33.2 \\
34.2 \\
32.7\end{array}$ \\
\hline
\end{tabular}

history of DM. Similarly nearly half of the respondents (46.9 $\%)$ had additional co-morbidity. More than half of patients $(52.3 \%)$ used oral hypoglycemic agent to manage their blood glucose level. Hundred sixty-nine $(43.1 \%)$ of patients never missed their diabetic follow up appointment in the past three month.

Additionally, nearly one-fourth of participants (26.8\%) reported that they did not attend diabetic education sessions while $(12 \%)$ of them attended regularly. It was also observed that one-fourth $(25.5 \%)$ of diabetic patients were member of Ethiopian diabetic association. The mean BMI was $27(\mathrm{SD} \pm 13)$ and $44.1 \%$ of respondents had normal BMI while $19.6 \%$ of respondents were obese. Seventeen point three percent (17.3\%) of patients had abdominal obesity (Table 2 \& Figure 1 ).

\section{Adherence status of study participants to physical acti- vity recommendations}

The study found that more than one third (38\%) of study participants were non-adherent to physical activity recommendations (Figure 2).

Assessment of diabetic health beliefs showed that, nearly three fourth (72.7) of participants had high perceived susceptibility, while proportion of diabetic patients with high perceived severity, perceived barrier and self-efficacy accounts for $54.6,43.9$ and $60.7 \%$, respectively. The study also found poor emotional and active support among 51 and $56.6 \%$ of respondents, respectively (Table 3 ).

On multivariable logistic regression analysis it was observed that patients' gender, abdominal obesity, perceived 
severity and self-efficacy were independent predictors of non-adherence to physical activity recommendations. Female patients had twice higher odds of non-adherence than males $($ AOR=2.029 $(1.2,-3.378))$. Similarly, patients who were not abdominally obese were 2.5 times more likely to be nonadherent to physical activity recommendations (AOR=2.5 (1.3, 4.84)). Likewise, patients with low perceived severity had 1.7 times higher odds of non-adherence than their counterparts (AOR=1.7 (1.052, 2.85)). Furthermore, patients with low selfefficacy were 2.6 times more likely to be non-adherent to physical activity recommendations $(\mathrm{AOR}=2.64(1.6,4.38))$ than a patient who had high self-efficacy (Table 4).

\section{Discussion}

In this study, $38 \%$ of study participants were nonadherent to physical activity recommendations. This finding is comparatively lower than results from other parts of Ethiopia including Sodo, Jimma, Harer and Yemen which reported physical activity non-adherence in more than two-third of diabetic patients $[13,23,24]$. However, its comparable with the study done in Singapore [25]. The discrepancy might arise from lifestyle differences between study settings, comparatively the

Table 2: Clinical characteristics of type 2 diabetic patients attending regular followup at public health facilities in Illubabor Zone, south west Ethiopia.

\begin{tabular}{|c|c|c|}
\hline Variables & Frequency $(\mathrm{N}=392)$ & Percent \\
\hline $\begin{array}{c}\text { Duration of DM } \\
\text { <1year } \\
\text { 2-5year } \\
\text { 6-10years } \\
>11 \text { years }\end{array}$ & $\begin{array}{c}27 \\
184 \\
92 \\
89\end{array}$ & $\begin{array}{r}6.9 \\
46.9 \\
23.5 \\
22.7\end{array}$ \\
\hline $\begin{array}{l}\text { Co morbidity } \\
\text { Yes } \\
\text { No } \\
\text { Don't know }\end{array}$ & $\begin{array}{c}184 \\
187 \\
21\end{array}$ & $\begin{array}{c}46.9 \\
47.7 \\
5.4\end{array}$ \\
\hline $\begin{array}{l}\text { Treatment type } \\
\text { Insulin } \\
\text { Oral hypoglycemic } \\
\text { Both } \\
\text { Life style modification }\end{array}$ & $\begin{array}{c}128 \\
205 \\
30 \\
29\end{array}$ & $\begin{array}{l}32.7 \\
52.3 \\
7.7 \\
7.4\end{array}$ \\
\hline $\begin{array}{c}\text { Family History } \\
\text { Yes } \\
\text { No } \\
\text { Don't know }\end{array}$ & $\begin{array}{l}182 \\
110 \\
100\end{array}$ & $\begin{array}{l}46.4 \\
28.1 \\
25.5\end{array}$ \\
\hline $\begin{array}{c}\text { Missed appointment } \\
\text { None } \\
\text { One time } \\
\text { Two times } \\
\text { Three and above }\end{array}$ & $\begin{array}{c}169 \\
127 \\
75 \\
21\end{array}$ & $\begin{array}{c}43.1 \\
32.4 \\
19.1 \\
5.4\end{array}$ \\
\hline $\begin{array}{l}\text { Diabetic education } \\
\text { Never atten } \\
\text { Sometimes attend } \\
\text { Regularly attend }\end{array}$ & $\begin{array}{c}105 \\
240 \\
47\end{array}$ & $\begin{array}{c}26.8 \\
61.2 \\
12\end{array}$ \\
\hline $\begin{array}{l}\text { Source of diabetic information } \\
\text { Media } \\
\text { Medical staff } \\
\text { Friends and family }\end{array}$ & $\begin{array}{c}21 \\
319 \\
52\end{array}$ & $\begin{array}{c}5.4 \\
81.4 \\
13.3\end{array}$ \\
\hline $\begin{array}{l}\text { Physical activity written instruction } \\
\text { Yes } \\
\text { No }\end{array}$ & $\begin{array}{c}51 \\
341\end{array}$ & $\begin{array}{l}13 \\
87\end{array}$ \\
\hline $\begin{array}{c}\text { DM association membership } \\
\text { Yes } \\
\text { No }\end{array}$ & $\begin{array}{l}100 \\
292\end{array}$ & $\begin{array}{l}25.5 \\
74.4\end{array}$ \\
\hline
\end{tabular}

\section{BMI}

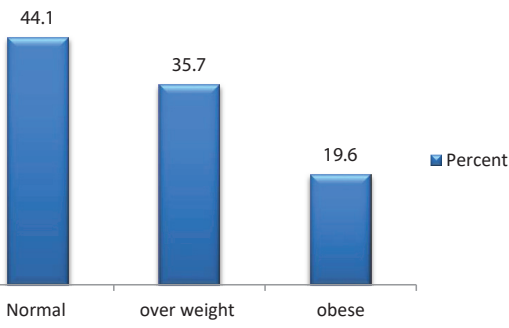

Figure 1: Anthropometric characteristics of type 2 diabetic patients attending regular follow-up at public health facilities in Illubabor Zone, southwestern Ethiopia.

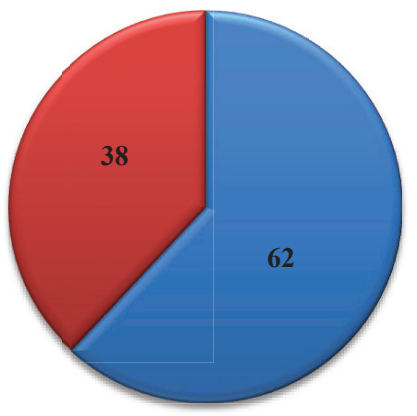

$\square$ Adherent

Non adherent

Figure 2: Adherence status of type 2 diabetic patients to physical activity recommendations attending regular follow-up at public health facilities in illubabor zone, southwestern Ethiopia.

Table 3: Diabetes health beliefs characteristics among type 2 diabetic patients attending regular follow-up at public health facilities in Illubabor Zone, Southwest Ethiopia.

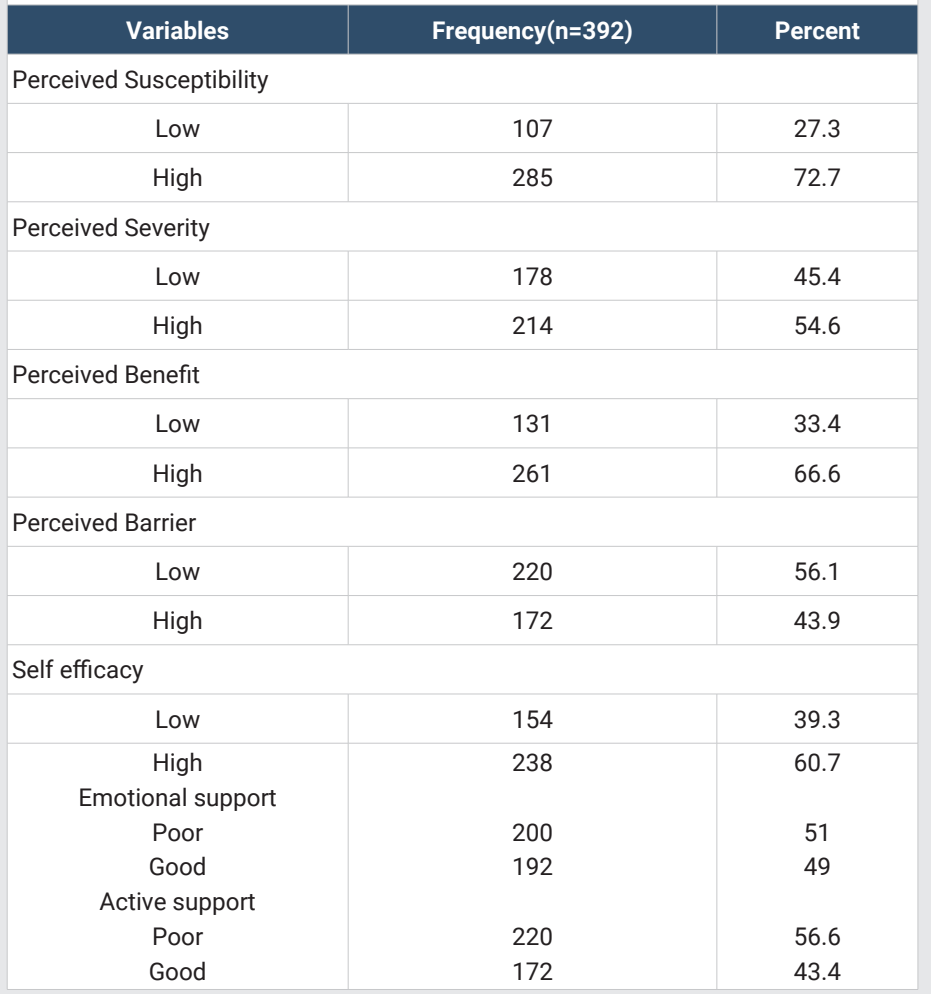

current study is conducted in small towns, most people from such settings commonly engaged in different agricultural and other labour-intensive activities. Additionally, because of the proximity of every district majority of people in such cities

Citation: Debalke R, Zinab B, Belachew T (2022) Non adherence to physical activity recommendations and associated factors among Type 2 Diabetic patients in Illubabor zone, South West Ethiopia. Glob J Obes Diabetes Metab Syndr 9(1): 001-006. DOI: https://dx.doi.org/10.17352/2455-8583.000054 
Table 4: Multivariable logistic regression model predicting non-adherence to physical activity recommendation among type 2 diabetic patients attending regular follow-up at public health facilities in Ilu Abba Bora Zone, Southwest Ethiopia.

\begin{tabular}{|c|c|c|c|c|c|}
\hline \multirow{3}{*}{ Variables } & \multicolumn{2}{|c|}{$\begin{array}{l}\text { Adherence status to physical activity } \\
\text { recommendation }\end{array}$} & \multirow{3}{*}{ COR(95\%C.I) } & \multirow{3}{*}{ AOR(95\% C.I) } & \multirow{3}{*}{$P$} \\
\hline & Non adherent & Adherent & & & \\
\hline & No. (\%) & No. (\%) & & & \\
\hline \multicolumn{6}{|c|}{ Gender } \\
\hline Female & $97(48.3)$ & $104(51.7)$ & $2.493(1.63,3.8)$ & $2.029(1.2,3.378)$ & 0.006 \\
\hline Male & $52(27.2)$ & $139(72.8)$ & 1 & 1 & \\
\hline \multicolumn{6}{|c|}{ Abdominal obesity } \\
\hline Yes & $46(67.7)$ & $22(32.3)$ & $4.5(2.5,7.8)$ & $2.5(1.3,4.84)$ & \\
\hline No & 103(31.8) & $221(68.2)$ & 1 & 1 & 0.007 \\
\hline \multicolumn{6}{|c|}{ Perceived Severity } \\
\hline Low & 83(46.7) & $95(53.3)$ & $2(1.3,3)$ & $1.7(1.052,2.85)$ & 0.031 \\
\hline High & $66(30.9)$ & 148(69.1) & 1 & 1 & \\
\hline \multicolumn{6}{|c|}{ Self-efficacy } \\
\hline Low & $92(59.8)$ & $62(40.2)$ & $4.7(3,7)$ & $2.64(1.6,4.38)$ & 0.010 \\
\hline High & $57(24)$ & $181(76)$ & 1 & 1 & \\
\hline
\end{tabular}

usually preferred to have a walk to move from one village to another, likewise in this study nearly half of the patients were living with diabetes for more than 6 years and also have high perceived severity towards diabetic complications, as patients live for long time with diabetes he/she likely have a better awareness which likely help them to adhere to lifestyle modifications.

In this study, females were more likely to be non-adherent than males which is similar with a study done in India [12]. The association can be explained by commonly observed sociocultural, economic and religious advantages given to males to engage in outdoor jobs and sport activities which helped them to be physically active. On the contrary, most females living in developing countries spend most of their time executing domestic tasks.

In the current study, a patient's abdominal obesity was found to be an independent predictor of non-adherence to physical activity recommendations. Patients who had abdominal obesity were more likely to be non-adherent; obesity is a consequence of energy imbalance with caloric intake exceeding energy expenditure. Lack of physical activity is thought to be a major contributor to obesity. Obese individuals might not be engaged in regular physical activities because of its associated reduced balance control, posture deficits and higher metabolic cost of walking compared to people with normal body weight [2628 ]. The result can also be explained by commonly observed psychological consequences of being overweight or obese which leads to lowered self-esteem and anxiety as a result most individuals will not have the self-confidence to visit public gymnasiums regularly. Consequently, they tend to gravitate towards low-activity lifestyles and become sedentary leading to develops situation wherein the less active people become the greater their risk of gaining still more weight, and the more weight they gain and the less likely they are to become more active.

In the current study, patients perceived severity diabetes was one of the independent predictors of physical activity non-adherence. In this study, patients who had low perceived severity about the disease were more likely to be non-adherent to physical activity recommendation, the result is consistent with Health Belief Model assumptions (HBM) [29]. Individual perception of disease severity can be affected by diverse factors but as ones opinion of how serious a condition and its consequences influence whether the person will to take healthrelated actions. A patient who perceives diabetes as a severe health problem is expected to be adherent to general healthy lifestyle recommendations in order to have better quality of life and prevention of complications.

The current study, also found that patients with low level of self-efficacy were non-adherent to physical activity recommendations, the finding is consistent with a metaanalysis done in china which report a consistent and strong association between increased self-efficacy level and better adherence to diabetic self-management behaviors. Similarly, it is also consistent with the study done in Jimma, which pointed out better adherence to physical activity recommendations among patients with high self-efficacy $[30,31]$. The association is supported by Bandura's theory of self-efficacy [32]. According to the theory, people generally do not try to do something new unless they think they can do it, self-efficacy is the strongest predictor of whether one practices exercise, a patient who doesn't engage in the recommended levels of physical exercise tend to have low exercise self-efficacymeaning they don't believe they can exercise, and perceive the presence of a significant barrier to exercise.

\section{Conclusion and recommendations}

The current study found physical activity recommendation non-adherence among more than one-third of study participants. Patient's non-adherence to physical activity recommendations was significantly affected by the patient's sex, abdominal obesity, level of perceived severity and selfefficacy. Thus evidence-based and patient centered health education packages should be delivered to improve diabetic health literacy additionally necessary efforts should be made to improve patients' self-efficacy towards regular physical activity during regular follows up.

\section{Authors' contributions}

All stated authors R.D, T.B and B.Z. were involved in the 
study from the inception to design, acquisition of data, analysis and interpretation and drafting of the manuscript. All authors read and approved the final manuscript.

\section{Acknowledgment}

The authors wish to acknowledge Jimma University for financial assistance, we are also grateful to participants of the study.

\section{References}

1. Alemseged F, Haileamlak A, Tegegn A, Tessema F, Woldemichael K, et al. (2012) Risk Factor of Chronic Non-Communicable Diseases at Gilel Gibe Field Research Centre in Southwest Ethiopia: Population Based Study. Ethiop J Health Sci 22: 19-28. Link: https://bit.ly/3zxBpcs

2. International Diabetes Federation. IDF diabetes atlas 2013.

3. Walelgne W, Yadeta D, Feleke Y (2016) Ethiopian National Guideline on Major NCDs 2016 Guidelines on Clinical and Programmatic Management of Major Non Communicable Diseases.

4. Naslafkih A, Sestier F (2003) Diabetes mellitus related morbidity, risk of hospitalization and disability. J Insur Med 35: 102-113. Link: https://bit.ly/3t6D2wi

5. Stratton IM, Adler Al, Neil HA, Matthews DR, Susan E, et al. (2000) Prospective Observational Study. BMJ 321: 405-412. Link: https://bit.ly/3pZfRSB

6. American Diabetics Association. Standards of Medical Care for Patients 2003. Link: https://bit.ly/3qX8KcV

7. Ciechanowski P, Katon W, Russo J, Walker E (2001) The Patient-Provide Relationship Attachment Theory and Adherence to Treatment in Diabetes. Am J Psychiatry 158: 29-35. Link: https://bit.ly/3zy3foB

8. Hernández-Ronquillo L, Téllez-Zenteno JF, Garduño-Espinosa J, GonzálezAcevez E (2003) Factors associated with therapy noncompliance in type-2 diabetes patients. Salud Publica Mex 45: 191-197. Link: https://bit.ly/31vMX3f

9. Melikian C, White TJ, Vanderplas A, Dezii CM, Chang E (2002) Adherence to oral antidiabetic therapy in a managed care organization: A comparison of monotherapy, combination therapy, and fixed-dose combination therapy. Clin Ther 24: 460-467. Link: https://bit.ly/3ztu8u6

10. Sharma B, Agrawal M (2017) Factors Affecting Adherence to Healthy Lifestyle Int J Pure App Biosci 5: 105-116. Link: https://bit.ly/3HJX3wV

11. Parajuli J, Saleh F, Thapa N, Ali L (2014) Factors associated with nonadherence to diet and physical activity among nepalese type 2 diabetes patients ; a cross sectional study. BMC Res Notes 7: 758. Link: https://bit.ly/3zJhCXD

12. Jadawala HD, Pawar AB, Patel PB, Patel KG, Patel SB, et al. (2017) Factors Associated With Non Adherence to Diet and Physical Activity among Diabetes Patients: A Cross Sectional Study. National Journal of Community Medicine 8: 68-73. Link: https://bit.ly/3nOKTHS

13. Hailu Chare Koyra BED (2018) Physical Exercise and Factors Affecting Among Adult Diabetic Patients at Wolaita Soddo University Teaching Referral Hospital, Southern Ethiopia. 8: 1-8. Link: https://bit.ly/3G209Ki

14. Kassahun A, Gashe F, Mulisa E, Rike WA (2015) Nonadherence and factors affecting adherence of diabetic patients to anti- diabetic medication in Assela General Hospital, Oromia Region, Ethiopia. J Pharm Bioallied Sci 8: 124-129. https://bit.ly/3HCOWSL
15. Hailu E, Mariam WH, Belachew T, Birhanu Z (2012) Self-care practice and glycaemic control amongst adults with diabetes at the jimma university specialized hospital in south-west Ethiopia: A cross-sectional study. African J Prim Heal Care Fam Med 4: 1-6. Link: https://bit.ly/3JLD8PX

16. Greca AM La, Bearman KJ (2002) The Diabetes Social Support QuestionnaireFamily Version: Evaluating Adolescents' Diabetes-Specific Support From Family Members. J Pediatr Psychol 27: 665-676. Link: https://bit.ly/3zvlCdT

17. World Health Organization (2009) Global Physical Activity Questionnaire.

18. World Health Organization (2000) Obesity:preventing and managing the global epidemic. World Heal Organ - Tech Rep Ser. Link: https://bit.ly/3t30qL1

19. Alricsson M (2013) Physical Activity Why and How? J Biosaf Heal Educ 01 1-2. https://bit.ly/336N3P2

20. Zhang JA, Wei Z, Li CG, Sun CB (2013) Piping system design of subsea manifold. Appl Mech Mater 321-324: 1779-1783. Link: https://bit.ly/3qQ4xrq

21. WHO (2008) Global Physical Activity Questionnaire (GPAQ) WHO STEP wise approach to NCD risk factor surveillance. Surveill Popul Prev Prev Noncommunicable Dis Dep 1-3. https://bit.ly/3zwR63n

22. Dyrstad SM, Edvardsen E, Hansen BH, Anderssen SA (2016) Waist circumference thresholds and cardiorespiratory fitness. J Sport Heal Sci 1-6.

23. Ayele K, Tesfa B, Abebe L, Tilahun T, Girma E (2012) Self care behavior among patients with diabetes in harari, eastern ethiopia: The health belief model perspective. PLoS One 7. Link: https://bit.ly/3nOKOUA

24. Tamirat A, Abebe L, Kirose G (2014) Prediction of physical activity among Type - 2 diabetes patients attending Jimma University specialized Hospital, southwest Ethiopia: Application of health belief model. Sci J Public Heal 2 524-531. Link: https://bit.ly/3t30IXJ

25. Nor Shazwani MN, Suzana S, Hanis Mastura Y, Lim CJ, Teh SC, et al. (2010) Assessment of physical activity level among individuals with type 2 diabetes mellitus at cheras health clinic, Kuala Lumpur. Malays J Nutr 16: 101-112. Link: https://bit.ly/3pXDLOQ

26. Youssef M (2014) The impact of obesity on walking and physical performance Egypt J Intern Med 26: 40-44. Link: https://bit.ly/3eXTJlw

27. Pataky Z, Armand S, Müller-Pinget S, Golay A, Allet L (2014) Effects of obesity on functional capacity. Obesity 22: 56-62. Link: https://bit.ly/3zwGKAD

28. Delextrat A, Matthew D, Cohen DD, Brisswalter J (2011) Effect of stride frequency on the energy cost of walking in obese teenagers. Hum Mov Sci 30 115-124. Link: https://bit.ly/3t2EVKD

29. Abraham C, Sheeran P (2016) The Health Belief Model.

30. Luo X, Liu T, Yuan X, Ge S, Yang J, et al. (2015) Factors influencing selfmanagement in Chinese adults with type 2 diabetes: A systematic review and meta-analysis. Int J Environ Res Public Health 12: 11304-11327. Link: https://bit.ly/3HJUgnt

31. Tamirat A, Abebe L, Kirose G (2014) Prediction of physical activity among Type-2 diabetes patients attending Jimma University specialized Hospital, southwest Ethiopia : Application of health belief model. Sci J Public Health 2 524-531. Link: https://bit.ly/3t30lXJ

32. Bandura A (1998) Self-Efficacy. In V. S. Ramachaudran (Ed.), Encyclopedia of human behavior. New York: Academic Press. (Reprinted in H. Friedman [Ed.] Encyclopedia of mental health. 4: 71-81. Link: https://bit.ly/3HF12KX

Citation: Debalke R, Zinab B, Belachew T (2022) Non adherence to physical activity recommendations and associated factors among Type 2 Diabetic patients in Illubabor zone, South West Ethiopia. Glob J Obes Diabetes Metab Syndr 9(1): 001-006. DOI: https://dx.doi.org/10.17352/2455-8583.000054 